University of Nebraska - Lincoln

DigitalCommons@University of Nebraska - Lincoln

\title{
Host location by Spalangia cameroni (Hymenoptera: Pteromalidae) in equine associated substrates
}

\author{
Erika T. Machtinger \\ University of Florida, irishtangerine@ufl.edu \\ Christopher J. Geden \\ USDA-ARS, Chris.geden@ars.usda.gov
}

Follow this and additional works at: https://digitalcommons.unl.edu/usdaarsfacpub

\footnotetext{
Machtinger, Erika T. and Geden, Christopher J., "Host location by Spalangia cameroni (Hymenoptera: Pteromalidae) in equine associated substrates" (2013). Publications from USDA-ARS / UNL Faculty. 1165. https://digitalcommons.unl.edu/usdaarsfacpub/1165
}

This Article is brought to you for free and open access by the U.S. Department of Agriculture: Agricultural Research Service, Lincoln, Nebraska at DigitalCommons@University of Nebraska - Lincoln. It has been accepted for inclusion in Publications from USDA-ARS / UNL Faculty by an authorized administrator of DigitalCommons@University of Nebraska - Lincoln. 


\title{
Host location by Spalangia cameroni (Hymenoptera: Pteromalidae) in equine associated substrates
}

\author{
Erika T. Machtinger ${ }^{\mathrm{a}, *}$, Christopher J. Geden ${ }^{\mathrm{b}}$ \\ a Entomology and Nematology Department, University of Florida, P.O. Box 110620, Gainesville, FL 32611, USA \\ ${ }^{\mathrm{b}}$ USDA-ARS, Center for Medical, Agricultural, and Veterinary Entomology, 1600 S. W. 23rd Drive, Gainesville, FL 32611, USA
}

\section{H I G H L I G H T S}

Substrate influenced host seeking of Spalangia cameroni at low host densities.

- With fewer hosts, Spalangia cameroni had greater flexibility for host seeking in substrates.

- Species of host did not have any effect on host seeking of Spalangia cameroni.

- Increased host:parasitoid ratio did not increase parasitoid progeny production.

- Spalangia cameroni appears to be a suitable candidate for release.

\section{A R T I C L E I N F O}

\section{Article history:}

Received 11 September 2012

Accepted 15 January 2013

Available online 23 January 2013

\section{Keywords:}

Musca domestic

Stomoxys calcitrans

Pteromalidae

Biological control

Substrates
G R A P H I C A L A B S T R A C T

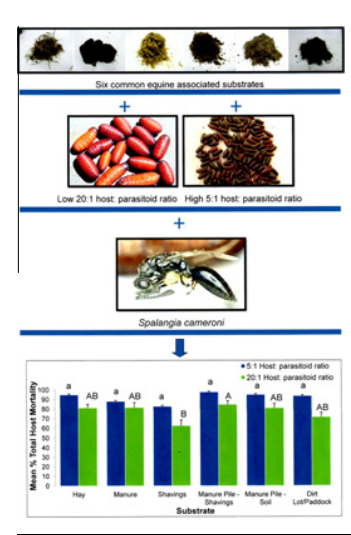

\begin{abstract}
A B S T R A C T
House flies, (Musca domestica L.) and stable flies (Stomoxys calcitrans L.) are common pests on equine facilities. Biological control of these flies with pupal parasitoids has become increasingly popular with horse owners but has not been evaluated on equine facilities. Little is known of the substrate preferences of filth fly parasitoids on equine facilities, but the success of release programs may be affected by microhabitat preferences. Spalangia cameroni Perkins was evaluated for location preferences for parasitization of house fly and stable fly puparia in six substrates commonly found on equine farms in Florida. Substrates were evaluated at 20:1 and 5:1 H:P ratios and during the experiment parasitoids had access to all substrates simultaneously. No differences were observed between filth fly host species in any of the measured parameters: total host mortality, parasitoid progeny production and residual host mortality. Significant effects of $\mathrm{H}: \mathrm{P}$ ratio on host mortality and residual mortality were found but not on progeny production. While there were significantly more hosts killed in the aged shavings than the fresh shavings at the 20:1 ratio, no differences were observed at the 5:1 ratio. Additionally, no differences were found in progeny production across substrates at the 20:1 ratio, but higher reproductive success was observed in several substrates at the 5:1 ratio. These results demonstrate that $S$. cameroni had substrate preferences but that these preferences were absent with reduced host density. This parasitoid species appears to be effective at parasitizing hosts in the common equine substrates of Florida.
\end{abstract}

(c) 2013 Elsevier Inc. All rights reserved.

\footnotetext{
* Corresponding author. Fax: +1 3523920190.

E-mail addresses: irishtangerine@ufl.edu (E.T. Machtinger), Chris.geden@ars.usda.gov (C.J. Geden).
} 


\section{Introduction}

Biological control of house flies, (Musca domestica L.), and stable flies, (Stomoxys calcitrans (L.), using pupal parasitoids (Hymenoptera: Pteromalidae) has been used in a variety of confined livestock facilities for many years. Pupal parasitoids used in augmentative control programs for filth flies is an alternative to chemical management and use on equine farms has the potential to reduce environmental contamination by reducing the need for insecticide applications and slow insecticide resistance development. Horse owners in particular have shown an increasing interest in the use of biological control agents equine (USDA, 2006; Machtinger, 2011) and commercial parasitoid products often are marketed specifically to this stakeholder group (Leppla and Johnson, 2010).

Though Pteromalid pupal parasitoids frequently are used for fly control, the results of augmentative parasitoid control programs on confined livestock and poultry operations have been inconsistent and evaluations on equine facilities are lacking. Several studies have documented parasitism and increased control of filth flies following releases (Morgan and Patterson, 1977; Rutz and Axtell, 1979; Morgan, 1980; Morgan and Patterson, 1990; Weinzierl and Jones, 1998; Skovgard, 2004; Geden and Hogsette, 2006), whereas others saw no effects on fly control (Petersen and Meyer, 1983; Andress and Campbell, 1994).

Substrate preferences of the released parasitoid species may influence parasitism rates and contribute to the variable effects of control seen in previous studies. Parasitism levels can vary in response to moisture (Legner, 1977; Smith and Rutz, 1991b; Geden, 1999) and host accessibility (Legner, 1977; Rueda and Axtell, 1985; Geden, 2002; Pitzer et al., 2011b). Surprisingly, little is known about microhabitat preferences and the effects of release rates on habitat preference for parasitism by Spalangia cameroni, the most common pupal parasitoid species of filth flies in Florida equine facilities (Pitzer et al., 2011a).

The probability of the success of a biological control program using pupal parasitoids on equine farms could be increased y matching parasitoid species to their preferred regional or local microhabitats. Knowledge of effects of parasitoid release rate on substrate preferences and the types of habitats likely to draw specific parasitoids could guide horse owners in the management of their facility.

The purpose of the present study was to examine habitat preferences of $S$. cameroni in the laboratory among six substrates that are commonly found at equine facilities in Florida with two hosts, house flies and stable flies, and at two different host:parasitoid $(\mathrm{H}: \mathrm{P})$ ratios. The goal was to determine if substrates used on equine facilities in Florida were suitable for parasitism by S. cameroni and if substrate preferences different with increased parasitoid application rates.

\section{Materials and methods}

\subsection{Test substrates}

Six substrates commonly found on equine facilities in Florida were evaluated for substrate preference by S. cameroni. These substrates had previously been observed to serve as pupariation sites for house fly and stable fly hosts on various equine facilities (Machtinger, 2011) (Table 1).

Substrates were collected during 1 week in the fall of 2010 at equine farms in Alachua County, FL. Neither area-wide pesticides nor insect growth regulators were used at the facilities. Accumulations on the surface to a maximum depth of $10-\mathrm{cm}$ were recovered. Samples were collected with a trowel, put in plastic freezer bags (Ziplock $^{\circledR}$, SC Johnson. Racine, WI), and immediately placed in a plastic cooler to protect from direct sunlight. A subsample of each substrate was weighed and dried in a drying oven at $45^{\circ} \mathrm{C}$ to determine the field moisture level. The remaining substrate was frozen at $-18{ }^{\circ} \mathrm{C}$ for $\geqslant 1$ week to kill any existing arthropods. To ensure homogeneity, individual substrates collected on different days were mixed thoroughly while frozen by breaking them with an ice pick.

Plastic cups (266 ml capacity, Plastic Container City, Brooklyn, New York) were filled with $200 \mathrm{~cm}^{3}$ of each of the six substrates. The substrates used are detailed in Table 1. Briefly, the substrates were: soiled hay of variable age from around a coastal Bermudagrass round bale (Hay), fresh manure collected from a mare fed perennial peanut hay and concentrated feed (Man), freshly soiled pine shavings with small amounts of waste perennial peanut hay from a stall kept horse (Shav), aged soiled pine shavings from a waste manure pile containing small amounts of waste perennial peanut hay (Mps), soiled sand bedding from an aged waste manure pile containing small amounts of waste hay Bermuda grass hay (Mpd), and soil mixed with variable aged manure from a dirt paddock (DL). Standardized weights of each substrate were used for each experiment. These weights varied because of differing substrate densities. Substrate densities were obtained by dividing the standardized weights used by the volume of each substrate.

Prior to inoculation with fly larvae, substrates were adjusted to a moisture level of $45 \%$ by drying at $45{ }^{\circ} \mathrm{C}$ (Geden, 1999) or adding deionized water with a misting spray bottle then lightly mixing with a probe. Moisture adjustments were made based on field collected moisture levels of each substrate as determined by the University

Table 1

Analysis and descriptions of six equine facility fly breeding substrates evaluated for pteromalid searching preferences.

\begin{tabular}{|c|c|c|c|c|c|}
\hline Substrate & Abbreviation & $\begin{array}{l}\text { Field collected } \\
\text { moisture content } \\
(\%)^{\mathrm{a}}\end{array}$ & $\begin{array}{l}\text { Density } \\
(\mathrm{g} / \mathrm{ml})\end{array}$ & $\begin{array}{l}\text { Standardized } \\
\text { weight }\end{array}$ & Narrative description \\
\hline Hay & Hay & 68.6 & 1.11 & $50 \mathrm{~g}$ & Hay + urine + manure (variable age) from around a coastal Bermudagrass round bale. \\
\hline Manure & Man & 78.2 & 1.66 & $100 \mathrm{~g}$ & $\begin{array}{l}\text { Fresh manure }(<12 \mathrm{~h} \text { old }) \text { collected from a mare fed perennial peanut hay and } \\
\text { concentrated feed. }\end{array}$ \\
\hline Shavings & Shav & 35.2 & 0.83 & $50 \mathrm{~g}$ & $\begin{array}{l}\text { Fresh pine shavings }(0.1-0.3-\mathrm{cm} \text { long })+\text { urine }+ \text { fresh manure }(<12 \mathrm{~h} \text { old })+\text { small } \\
\text { amounts of waste perennial peanut hay from a stall kept horse. }\end{array}$ \\
\hline $\begin{array}{c}\text { Manure pile } \\
\text { - } \\
\text { shavings }\end{array}$ & Mps & 54.9 & 0.89 & $50 \mathrm{~g}$ & $\begin{array}{l}\text { Pine shavings ( size as above) +urine }+ \text { manure from a manure pile }(>72 \mathrm{~h} \text { old }) \\
\text { containing small amounts of waste perennial peanut hay. }\end{array}$ \\
\hline $\begin{array}{l}\text { Manure pile } \\
\quad \text { - soil }\end{array}$ & Mpd & 59.7 & 2.24 & $100 \mathrm{~g}$ & $\begin{array}{l}\text { Soil }+ \text { urine }+ \text { manure }(>72 \mathrm{~h} \text { old }) \text { from an aged manure pile containing small amounts } \\
\text { of waste hay from a mare fed coastal Bermudagrass hay and concentrated feed. }\end{array}$ \\
\hline Dirt lot & DL & 22.6 & 2.50 & $100 \mathrm{~g}$ & Soil + urine + manure (variable age) from a dirt paddock. \\
\hline
\end{tabular}

${ }^{\text {a }}$ As determined by the University of Florida Analytic Services Laboratory. 
of Florida Analytical Services Laboratory (Gainesville, FL). The rate of daily substrate moisture loss was determined in a preliminary drying experiment. Three samples of each substrate at the standardized weight were air dried in the room where the experiment occurred. After $24 \mathrm{~h}$, the substrates were weighed and the rate of moisture loss recorded. During the experiments, substrates were rehydrated daily at the predetermined rate to maintain $45 \%$ moisture by lightly misting with deionized water in a spray bottle.

\subsection{House flies, stable flies and parasitoids}

Third instar house flies or stable flies were obtained from the USDA-ARS, Center for Medical, Agriculture and Veterinary Entomology (CMAVE) insecticide-susceptible colony. Larvae were reared in a diet described by Hogsette (1992). This diet consisted of $3800 \mathrm{~L}$ water and $5000 \mathrm{~L}$ of F.R.M fly diet mix (50\% wheat bran, $30 \%$ alfalfa meal and 20\% corn meal) manufactured in Marion County, Florida.

Active $S$. cameroni females were obtained from an established colony maintained by at the USDA-ARS, CMAVE in Gainesville, FL. This colony was originally obtained by author CJG from a dairy in Gilchrist County, FL in November, 2010. Weekly maintenance consisted of providing parasitoids with 2-day-old house fly puparia at a $\mathrm{H}: \mathrm{P}$ ratio of $5: 1$ in $32.5 \times 32.5 \times 32.5-\mathrm{cm}$ cages (MegaView Science, Taiwan) and held at $25^{\circ} \mathrm{C}, 80 \% \mathrm{RH}$ under constant darkness. For each experiment, parasitoids were anesthetized by chilling on a cooling table to count and identify females.

\subsection{Bioassay}

House fly and stable fly hosts were tested individually. One day prior to expected pupariation, 100 3rd instars of the respective fly species were counted and placed on the surface of the experimental cups containing one of the six substrates for each trial and host species. Six cups were used per trial to represent each substrate for a total of 600 hosts per release arena. The same numbers of larvae were placed in control cups containing $50 \mathrm{~g}$ of moistened vermiculite that served a visual confirmation of pupariation and controls for fly mortality and parasitism. Cups were covered with cotton muslin fabric secured with plastic lid rims and larvae from both control and experimental cups were held at $27^{\circ} \mathrm{C}, 80 \% \mathrm{RH}$ and provided constant light, allowing them to pupariate naturally in each cup.

Release arenas $(60 \times 60 \times 60-\mathrm{cm})$ composed of 2 side panels of polyester netting $(72 \times 26$ mesh) for ventilation and 2 sides with transparent plastic sheeting (MegaView Science, Taiwan) were used for this study. When $95 \%$ of the fly larvae in the control cups were visually observed to have pupated, approximately 2 days after the introduction of larvae, the fabric covers were removed and 1 representative cup of each of the six substrates were placed randomly in a circle array around a central release point in each of the trial arenas. Parasitoids were released in the center of the array and given $72 \mathrm{~h}$ to parasitize hosts (Pitzer et al., 2011b). Two H:P ratios were tested for each host, a 5:1 and 20:1 ratio that consisted of 120 and 30 individual female parasitoids, respectively, with 600 total fly puparia in each release arena.

After 3 days, the cups were removed from the arenas. Puparia from each experimental cup were isolated by water flotation and air dried (Lee and Toyama, 1990). Puparia from control cups were sifted from vermiculite in a \#12 sieve. Puparia were maintained in covered $60-\mathrm{cm}^{3}$ plastic cups at $25{ }^{\circ} \mathrm{C}$ and approximately $80 \% \mathrm{RH}$ with constant light for adult fly eclosion. Adult flies were counted after 7 days. Flies and empty puparia were removed and the remaining puparia were held for 4 weeks for parasitoid emergence. When it was determined that parasitoid emergence in experimental cups had ceased for 1 week (ca. 6 weeks after test set up), puparia from the release arenas and control cups were examined for the presence of emergence holes to determine the number producing adult parasitoids. Emergence holes were used as the metric for parasitoid progeny production because adults of this species occasionally re-enter host puparia if there are no hosts available. Remaining puparia from control cups were counted for residual mortality, or those that did not produce a parasitoid or fly.

Three replicates were conducted on each test date for each species and H:P ratio and the entire experiment was replicated on 3 dates using different cohorts of parasitoids and flies.

\subsection{Statistical analysis}

Data were analyzed with a full factorial analysis of variance (ANOVA) using JMP v. 9 (SAS Institute Inc., Cary, NC 2010). Separate analyses were conducted for 3 response variables; (1) host mortality, defined as the number of puparia not producing an adult fly/total number of recovered puparia, (2) progeny production which is characterized as the number of puparia producing a parasitoid/total number of recovered puparia, and (3) residual host mortality, or unexplained host mortality, which equaled the number of puparia not producing a fly or parasitoid/number of recovered puparia.

Substrate, host species, and $\mathrm{H}: \mathrm{P}$ ratio as well as their interaction were evaluated as independent factors. Response variables were analyzed by $\mathrm{H}: \mathrm{P}$ ratio separately to further evaluate the significant interaction term in the full factorial ANOVA. No significance of fly species, species $\mathrm{xH}$ :P ratio or species $\times$ substrate $\times \mathrm{H}$ :P ratio was observed for any of the measured parameters, therefore data were pooled for further analysis.

Percentage data were normalized with an arcsine square root transformation; results in tables and text are reported as original units. Means were calculated for $\mathrm{H}: \mathrm{P}$ ratio and were separated with Tukey's HSD test for comparison $(\alpha=0.05)$.

\section{Results}

Natural substrate moisture content as collected from the field ranged from $22.6 \%$ in the DL to $78.2 \%$ in the Man (Table 1). The density of each substrate was variable, measuring between $0.83 \mathrm{~g} / \mathrm{ml}$ and $2.5 \mathrm{~g} / \mathrm{ml}$. Density did not appear to affect any of the measured parameters. Substrates with the highest host mortality and lowest host mortality were very similar in density $(0.89-0.83 \mathrm{~g} / \mathrm{ml}$, respectively).Other substrates with no significant difference in host mortality ranged in density from 1.11 to $2.50 \mathrm{~g} / \mathrm{ml}$.

Overall, host mortality was influenced by substrate, $\mathrm{H}: \mathrm{P}$ ratio and there was a species $x$ substrate in the full factorial ANOVA (Table 2). Progeny production of $S$. cameroni was influenced by substrate and significant species $\times$ substrate and substrate $\times \mathrm{H}: \mathrm{P}$ ratio interactions. Substrate had a significant influence on residual host mortality as well as $\mathrm{H}: \mathrm{P}$ ratio and the interaction of substrate $\times \mathrm{H}: \mathrm{P}$ ratio.

The $\mathrm{H}: \mathrm{P}$ ratios were analyzed separately to further refine interaction effects found in the full factorial analysis (Table 3). Cumulatively, at the 20:1 H:P ratio, parasitoids induced significantly greater most mortality in the Mps (84.6\%) than the Shav (62.6\%). There were no observed differences in progeny production at the by substrate at the 20:1 ratio but differences in residual mortality were observed between the Man (27.2\% residual mortality) and three other substrates, the Shav, Mps and DL (16.2-19.0\% residual mortality).

At the 5:1 ratio, there was no significant difference in host mortality or residual mortality in any of the substrates. Host mortality was high, ranging from $82.7 \%$ to $97.7 \%$ (Shave and Mps, respectively). However, differences were observed in progeny production at the 5:1 ratio that was not seen in the 20:1 ratio. A higher 
Table 2

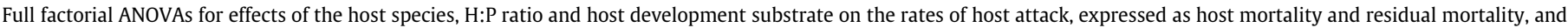
Spalangia cameroni Perkins progeny production in experimental arenas containing equine-generated substrates.

\begin{tabular}{|c|c|c|c|c|c|c|}
\hline \multirow[b]{2}{*}{ Variable } & \multicolumn{2}{|c|}{ Percent total host mortality } & \multicolumn{2}{|c|}{ Percent parasitoid progeny production } & \multicolumn{2}{|c|}{ Percent residual host mortality } \\
\hline & $F$ & $P$ & $F$ & $P$ & $F$ & $P$ \\
\hline Fly species ${ }^{1}$ & 0.47 & $0.3113 N S$ & 0.88 & $0.3485 N S$ & 0.01 & $0.9356 \mathrm{NS}$ \\
\hline Substrate $^{2}$ & 5.9 & $<0.0001$ & 4.26 & 0.0010 & 2.27 & 0.0486 \\
\hline H:P ratio ${ }^{3}$ & 4.99 & 0.0266 & 0.77 & $0.3824 \mathrm{NS}$ & 4.17 & 0.0424 \\
\hline Species $\times$ substrate & 3.99 & 0.0018 & 3.65 & 0.0035 & 1.25 & $0.2863 \mathrm{NS}$ \\
\hline Species $\times \mathrm{H}$ :P ratio & 0.11 & $0.7387 \mathrm{NS}$ & 0.00 & $0.9882 \mathrm{NS}$ & 0.63 & $0.4274 \mathrm{NS}$ \\
\hline Substrate $\times \mathrm{H}: \mathrm{P}$ ratio & 2.19 & $0.0570 \mathrm{NS}$ & 2.36 & 0.0410 & 2.65 & 0.0238 \\
\hline Species $\times$ substrate $\times$ H:P ratio & 1.85 & $0.1042 N S$ & 2.09 & $0.0683 \mathrm{NS}$ & 1.18 & $0.3185 N S$ \\
\hline
\end{tabular}

$P \leqslant 0.05$.

1 Fly species were house fly, Musca domestica L. and stable fly, Stomoxys calcitrans (L).

2 Fly Puparia in substrates of hay; manure; shavings; manure pile - shavings; manure pile - soil; and dirt lot.

${ }^{3} \mathrm{H}: \mathrm{P}=$ host:parasitoid ratios which included ratios of $5: 1$ and $20: 1$

Table 3

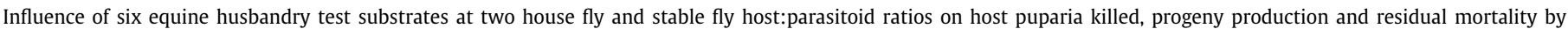
Spalangia cameroni Perkins.

\begin{tabular}{|c|c|c|c|c|}
\hline Ratio & Substrate & Total host mortality $(\bar{x} \% \pm$ SEM $)$ & Parasitoid progeny production $(\bar{x} \% \pm$ SEM $)$ & Residual host mortality $(\bar{x} \% \pm$ SEM) \\
\hline \multirow[t]{7}{*}{$5: 1$} & Hay & $94.9+1.2^{\mathrm{a}}$ & $66.9+2.9^{\mathrm{a}}$ & $28.2 \pm 2.1^{\mathrm{a}}$ \\
\hline & Manure & $88.0 \pm 5.6^{\mathrm{a}}$ & $45.1 \pm 6.1^{\mathrm{b}}$ & $42.9 \pm 5.5^{\mathrm{a}}$ \\
\hline & Shavings & $82.7 \pm 5.3^{\mathrm{a}}$ & $52.1 \pm 6.7^{\mathrm{ab}}$ & $33.4 \pm 5.0^{\mathrm{a}}$ \\
\hline & Manure pile - shavings & $97.7 \pm 0.7^{\mathrm{a}}$ & $67.4 \pm 3.4^{\mathrm{a}}$ & $30.4 \pm 3.0^{\mathrm{a}}$ \\
\hline & Manure pile - soil & $94.9 \pm 2.0^{\mathrm{a}}$ & $55.8 \pm 3.1^{\mathrm{ab}}$ & $39.1 \pm 3.3^{\mathrm{a}}$ \\
\hline & Dirt lot & $93.6 \pm 2.6^{\mathrm{a}}$ & $61.4 \pm 3.5^{\mathrm{ab}}$ & $32.2 \pm 2.8^{\mathrm{a}}$ \\
\hline & ANOVA $\mathrm{F}(\mathrm{df}=5,120)$ & 2.3377 & 4.4511 & 1.148 \\
\hline \multirow[t]{7}{*}{$20: 1$} & Hay & $81.2 \pm 3.9^{\mathrm{ab}}$ & $58.8 \pm 4.9^{\mathrm{a}}$ & $22.4 \pm 1.8^{\mathrm{ab}}$ \\
\hline & Manure & $81.5 \pm 5.2^{\mathrm{ab}}$ & $54.5 \pm 5.7^{\mathrm{a}}$ & $27.2 \pm 1.9^{\mathrm{a}}$ \\
\hline & Shavings & $62.6 \pm 5.9^{\mathrm{b}}$ & $44.0 \pm 6.6^{\mathrm{a}}$ & $18.6 \pm 2.7^{\mathrm{b}}$ \\
\hline & Manure pile - shavings & $84.6 \pm 3.9^{\mathrm{a}}$ & $63.5 \pm 5.2^{\mathrm{a}}$ & $21.1 \pm 2.1^{\mathrm{ab}}$ \\
\hline & Manure pile - soil & $80.8 \pm 4.7^{\mathrm{ab}}$ & $64.6 \pm 4.2^{\mathrm{a}}$ & $16.2 \pm 1.2^{\mathrm{b}}$ \\
\hline & Dirt lot & $71.3 \pm 4.7^{\mathrm{ab}}$ & $52.4 \pm 5.3^{\mathrm{a}}$ & $19.0 \pm 2.2^{\mathrm{b}}$ \\
\hline & ANOVA $\mathrm{F}(\mathrm{df}=5,102)$ & 2.7917 & 2.0712 & 3.4870 \\
\hline
\end{tabular}

Within each host:parasitoid ratio, means in a column followed by the same letter are not significantly different (Tukey's HSD test, $\alpha=0.05$ ).

percentage of puparia produced parasitoid progeny in the Mps and Hay substrates (66.9 and $67.4 \%$ progeny, respectively) than the Man (45.1\% progeny) when there were a greater number of parasitoids present per host. There was no significant difference between the substrates on residual host mortality.

\section{Discussion}

Although previous studies have examined the role of microhabitat on filth fly parasitoid searching behavior, none have included substrates that are found on equine facilities (Petersen and Meyer, 1983; Rueda and Axtell, 1985; Smith and Rutz, 1991a,b; Geden, 1999,2002 ). Our results demonstrate that $S$. cameroni is effective at locating hosts across the range of substrates typically encountered on Florida equine facilities and reinforce the importance of microhabitat associations on $S$. cameroni, especially when hosts are in abundant supply. These results further suggest that greater numbers of parasitoids per host (crowding) diminish habitat discrimination by S. cameroni, and that this results in higher overall host mortality in those substrates.

Little is known about the qualities of different substrates that affect parasitoid searching preferences or ability. In some cases, differential host location may be a result of density or textural factors that limit the ability of parasitoids to forage successfully. In a field survey, Smith and Rutz (1991a) determined that S. cameroni preferred loose substrates. Geden (2002) found that searching by $S$. cameroni in the laboratory was hindered substantially in dense sandy loam soil. In the present study, substrate density did not appear to be a factor in the success of host attack, although none of the tested substrates were as dense as the soil in the latter study
(Geden, 2002). Indeed, the density and texture was similar between the most and least preferred substrate at the 20:1 ratio ( 0.89 and $0.83 \mathrm{~g} / \mathrm{ml}$, respectively) (Table 1 ).

The lack of density textural influence on substrate preference suggests that cues other than physical and textural properties play a role in host location. Our results indicated that substrates containing relatively fresh manure were less preferred by $S$. cameroni. Considering this, chemical cues may have a greater influence on habitat selection that the physical characteristics of the substrate. Carbon dioxide $\left(\mathrm{CO}_{2}\right)$ emissions increase as horse manure decomposes (Jeanbourquin and Guerin, 2007). It is possible that increased $\mathrm{CO}_{2}$ emissions from aged manure serve as a semiochemical cue for attracting $S$. cameroni to the aged equine substrates where stable fly hosts are more likely to be found (Skoda et al., 1993). The results also suggest that parasitoid releases may be more effective if areas with aging manure are targeted, especially waste manure piles with a pine shavings base.

A greater percent of host mortality and residual mortality was observed on all substrates when more female parasitoids were present, but the percent of parasitoid progeny production was not different between $\mathrm{H}$ : $\mathrm{P}$ ratios. This is in contrast to the findings of Legner (1967) who saw increased progeny production with increased numbers of female $S$. cameroni. In the current study, the lack of increased progeny production when more females were present may be due to increased parasitoid host feeding (Geden, 1999) or superparasitim discrimination (Legner, 1967; Wylie, 1971a, 1972). Propp and Morgan (1983) determined that Spalangia endius Walker could discriminate and avoid ovipositing in previously parasitized pupae, but only after drilling into the puparia. This behavior may be shared with $S$. cameroni. Under population 
pressure, the assessment and subsequent host-drilling to avoid superparasitism could be potentially fatal to the developing fly or wasp immature, increasing overall host mortality and decreasing successful progeny production. In this way, increasing the numbers of parasitoids released in augmentative programs may have a proportionally greater impact on fly mortality than on progeny production.

The results of these studies demonstrate that this species shows considerable plasticity in its searching behavior, and that host availability can mediate innate substrate preferences. Overall, substrate effects on S. cameroni were only modest at the "high" $\mathrm{H}: \mathrm{P}$ ratio of 20:1 and were absent when hosts were in short supply. In a related study, Geden (1999) found that S. cameroni had a strong preference for dry poultry manure at high $(50: 1) \mathrm{H}: \mathrm{P}$ densities but that moisture preferences were much weaker at a ratio of $2.5: 1$. It is possible that the "high" $\mathrm{H}: \mathrm{P}$ ratio used in the present study (20:1) was not high enough to reveal the full extent of innate preferences for the substrates tested. However, in augmentative release programs, the demonstrated behavioral plasticity would be beneficial and expected to result in broad distribution of host mortality among accessible substrates because high parasitoid abundance should result in spillover away from the preferred substrates. In equine facilities with a range of suitable substrates for fly development, high numbers of released parasitoids may ensure parasitism in all substrates.

\section{Conclusions}

In summary, this is the first study to our knowledge to evaluate the searching behavior and preferences of $S$. cameroni in substrates found on horse farms. House flies and stable flies were equally vulnerable to parasitism and none of the substrates tested fell outside the range of moisture and density properties that have previously been found to limit searching behavior by this species. Innate preferences among these substrates were small and were overwhelmed when parasitoid abundance was high. It does not appear as though equine-generated substrates would negatively influence the success of filth fly parasitism by $S$. cameroni. Therefore, these results suggest that $S$. cameroni is a suitable candidate for augmentative releases for fly management programs on Florida horse farms. Further research is needed to determine appropriate release rates for such facilities, but the results indicate that sustained releases would be required to keep fly mortality high enough to provide satisfactory control.

\section{Acknowledgments}

Thanks to Dr. Norman Leppla and Dr. Jerome Hogsette for reviewing an early draft of this manuscript and to Rachel Dillard and Dana Bell for their help with fly rearing. This work was supported in part by funding from NIFA and the Extension Integrated Pest Management Coordination and Support Program (EIPM-CS).

\section{References}

Andress, E.R., Campbell, J.B., 1994. Innundative releases of pteromalid parasitoids (Hymenoptera: Pteromalidae) for the control of stable flies, Stomoxys calcitrans (L.) (Diptera: Muscidae) at confined cattle installations in west central Nebraska. Journal of Economic Entomology 87, 714-722.
Geden, C.J., 1999. Host location by house fly (Diptera: Muscidae) parasitoids in poultry manure at different moisture levels and host densities. Environmental Entomology 28, 755-760.

Geden, C.J., 2002. Effect of habitat depth on host location by five species of parasitoids (Hymenoptera: Pteromalidae, Chalcididae) of house flies, Musca domestica L. (Diptera: Muscidae) in three types of substrates. Environmental Entomology 31, 411-417.

Geden, C.J., Hogsette, J.A., 2006. Suppression of house flies (Diptera: Muscidae) in Florida poultry houses by sustained releases of Muscidifurax raptorellus and Spalangia cameroni (Hymenoptera: Pteromalidae). Environmental Entomology 35, 75-82.

Jeanbourquin, P., Guerin, P.M., 2007. Chemostimuli implicated in selection of oviposition substrates by the stable fly Stomoxys calcitrans. Medical and Veterinary Entomology 21, 209-6216.

Lee, C.N., Toyama, G.M., 1990. Ovipositional preference exhibited by Musca sorbens (Diptera: Muscidae) to feces of cows fed different rations. Environmental Entomology 19, 1296-1298.

Legner, E.F., 1977. Temperature, humidity and depth of habitat influencing host destruction and fecundity of muscoid fly parasites. Entomophaga 22, 199-206.

Leppla, N.C., Johnson, K., 2010. Guidelines for purchasing and using commercial natural enemies and biopesticides in Florida and other states. IPM-146, University of Florida Institute of Food and Agricultural Sciences.

Machtinger, E.T., 2011. Studies on the field ecology, breeding biology and parasitism of house flies, Musca domestica, and stable flies, Stomoxys calcitrans, (Diptera: Muscidae) to improve integrated pest management for North Florida small equine farms. Masters Thesis, University of Florida, Gainesville.

Morgan, P.B., 1980. Sustained releases of Spalangia endius (Hymenoptera: Pteromalidae) for the control of Musca domestica (L.) and Stomoxys calcitrans (L.) (Diptera: Muscidae). Journal of Kansas Entomology Society 53, 367-372.

Morgan, P.B., Patterson, R.S., 1977. Sustained releases of Spalangia endius to parasitize field populations of three species of filth breeding flies. Journal of Economic Entomology 70, 450-452.

Morgan, P.B., Patterson, R.S., 1990. Efficiency of target formulations of pesticides plus augmentative releases of Spalangia endius Walker (Hymenoptera: Pteromalidae) to suppress populations of Musca domestica L. (Diptera: Muscidae) at poultry ranches in the southeastern United States. In: Rutz, D.A. Patterson, R.S. (Eds.), Biocontrol of arthropods affecting livestock and poultry. Westview, Boulder, CO, pp. 69-78.

Petersen, J.J., Meyer, J.A., 1983. Host preference and seasonal distribution of Pteromalid parasites (Hymenoptera: Pteromalidae) of stable flies and house flies (Diptera: Muscidae) associated with confined livestock in eastern Nebraska. Environmental Entomology 12, 567-571.

Pitzer, J.B., Kaufman, P.E., Hogsette, J.A., Geden, C.J., Tenbroeck, S.H., 2011a. Seasonal abundance of stable flies and filth fly pupal parasitoids (Hymenoptera: Pteromalidae) at Florida equine facilities. Journal of Economic Entomology 104, 1108-1115.

Pitzer, J.B., Kaufman, P.E., Geden, C.J., Hogsette, J.A, 2011b. The ability of selected pupal parasitoids (Hymenoptera: Pteromalidae) to locate stable fly hosts in soiled equine bedding substrate. Environmental Entomology 40, 88-93.

Rueda, L.M., Axtell, R.C., 1985. Comparison of hymenopterous parasites of house-fly Musca domestica (Diptera, Muscidae), puparia in different livestock and poultry production systems. Environmental Entomology 14, 217-222.

Rutz, D.A., Axtell, R.C., 1979. Sustained releases of Muscidifurax raptor (Hymenoptera: Pteromalidae) for house fly (Musca domestica L.) control in two types of caged-layer houses. Environmental Entomology 8, 1105-1110.

Skoda, S.R., Thomas, G.D., Campbell, J.B., 1993. Abundance of the immature stages of the house fly (Diptera: Muscidae) from five areas in beef cattle feedlot pens. Journal of Economic Entomology 86, 455-461.

Skovgård, H., 2004. Sustained releases of the pupal parasitoid Spalangia cameron (Hymenoptera: Pteromalidae) for control of house flies, (Diptera: Muscidae) and stable flies (Diptera: Muscidae) on dairy farms in Denmark. Biological Control 30, 288-297.

Smith, L., Rutz, D.A., 1991a. Seasonal and relative abundance of hymenopterous parasitoids attacking house fly puparia at dairy farms in Central New York. Environmental Entomology 20, 661-668.

Smith, L., Rutz, D.A., 1991b. Relationship of microhabitat to incidence of house fly (Diptera: Muscidae) immatures and their parasitoids at dairy farms in Central New York. Environmental Entomology 20, 669-674.

(USDA) United States Department of Agriculture, 2006. Equine 2005, Part II: Changes in the U.S. Equine Industry. 1998-2005 USDA-APHIS-VS, CEAH, Fort Collins, CO \#N452-0307.

Weinzierl, R.A., Jones, C.J., 1998. Releases of Spalangia nigroaenea and Muscidifurax zaraptor (Hymenoptera: Pteromalidae) increase rates of parasitism and total mortality of stable fly and house fly (Diptera: Muscidae) puparia in Illinois cattle feedlots. Journal of Economic Entomology 91, 1111-1121. 